\title{
Professional mastermind groups Lessons from the ALA Leadership Institute
}

magine a free business tool that is adaptable to all types of libraries and can benefit librarians at every level to become more effective and successful. It exists with a mastermind group. There are numerous examples of mastermind groups throughout history.

In 1727 Benjamin Franklin with several colleagues formed the Junto Group, a club created for mutual improvement. ${ }^{1}$ Andrew Carnegie believed being part of a mastermind group was essential to his success. However, Napoleon Hill officially introduced the term master mind in his 1928 course "The Law of Success" and expanded the idea in his 1937 book Think and Grow Rich to describe the undeniable value of having a group of individuals providing outside perspective, tools, and motivation to bring each other's success to another level.

"The Law of Success" defines the mastermind as "a mind that is developed through the harmonious co-operation of two or more people who ally themselves for the purpose of accomplishing any given task." 2

Mastermind groups do not belong just in a commercial setting. The 2018 ALA Leadership Institute made this evident when mastermind groups were heavily used for problem solving in various library types and librarian roles.

Using the ALA Leadership Institute and my experience as a small business owner as examples, this article will discuss the nuts and bolts of forming a successful, professional mastermind group.

When making the decision to create a mastermind group several things need to be considered. First, the size of the group. For both my personal business group and the ALA Leadership Institute, six members composed a group. This size is a large enough to allow for diverse, unique opinions and advice, yet small enough to remain fairly intimate and allow members time for their own situations.

Creating a group of individuals who have varied experiences, skills, and viewpoints is crucial. For example, my business group was composed of a bookkeeper, a web designer, an attorney, a Mary Kay salesperson, a photographer, and myself-a financial planner. This was a mixture of service and product sales, a combination of creative and practical thinkers, and right-brained and left-brained individuals.

The ALA Leadership Institute by contrast, sorted us into cohorts based upon what type of library we worked in-public, academic, and other, including corporate and special libraries. However, we were diverse both in

Susan A. Schreiner is access services librarian at Pittsburg State University, email: sschreiner@pittstate.edu

(c) 2019 Susan A. Schreiner 
size of institutions and geographical locations. Regardless of how the team is formed, one characteristic for a successful group is crucial-all members must be willing to work hard on the problems of the other members.

Once the participants are selected, a structure for the meetings must be developed by the group to facilitate buy-in and a promise for all members to abide by this arrangement. Length of the meeting, time appropriated to members, location, and what will be accomplished during the meeting must be decided as a group.

For the ALA Leadership Institute, each member wrote a problem scenario they were facing in their current position. The Institute scheduled time each day for the group to review the scenario of one member, usually for 45 minutes. During this time, the problem scenario was reviewed and all six members discussed potential solutions and actions, while the author answered additional questions.

In contrast, my business group chose a different structure. We met for two hours, with the first 30 minutes being spent on a business topic presented by one member, then dedicated 15 minutes to each member to discuss whatever pain they were feeling in their business. Fifteen minutes may not seem like much time, but when six people are focused on one situation, one client issue, one piece of advertising, etc., the results can be astounding. A timer or an assigned time keeper is a good way of ensuring that each person gets their allotted time and that the meeting continues in a productive manner.

Like everything else, eventually it will come time for the group to end or transform. If the sessions are not productive, if the focus seems to be more on talking than focusing on problems, or if one or more members get their major issues solved, the group may experience fatigue and need to reevaluate how the meetings are run or if they need to continue. If the group has served its purpose, it is acceptable to disband or take a hiatus. Simply decide to stop meeting, or pick a timeline for revisiting the idea of a mastermind group (say in six months) and disband.

It is a little trickier when the group is continuing to be productive, but that productivity is harmed by members who don't show up, who don't complete tasks they need to, or who only focus on their own issues. If members are not contributing to the group, then either ask them to leave or disband and reform with more productive members. While this may seem cruel, wasting the time of the actively participating members is not acceptable.

The 2018 ALA Leadership Institute worked very hard for four-and-a-half days to install the values, drive, and inspiration needed to be the best library leaders possible. It also demonstrated that leadership cannot exist in a vacuum, and that the single best resource we will ever have in our professional careers is a group of professional advocates working hard to help solve the problems and challenges we will all encounter.

Each attendee gained new ideas, skills, and coping methods for dealing with some of the most pressing problems existing in our libraries. Taking the time to find a strong cohort and developing a mastermind group will also provide access to this valuable and empowering influence.

\section{Notes}

1. "Junto Club," Benjamin Franklin Historical Society, accessed December 6, 2018, http://www.benjamin-franklin-history.org /junto-club/.

2. Napoleon Hill, The Law of Success in Sixteen Lessons: Teaching, for the First Time in the History of the World, the True Philosophy upon which all Personal Success is Built (Meriden: Ralston University Press, 1939), https://ia802905.us.archive.org/3 /items/Law_Of_Success_in_16_Lessons/law -of-success-napoleon-hill.pdf. $\approx$ 